\title{
Society for Computers in Psychology Editorial
}

This issue of Behavior Research Methods comprises, in part, articles based on presentations at the 35th Annual Meeting of the Society for Computers in Psychology (SCiP). SCiP is a society that brings together psychologists interested in techniques and issues surrounding the use of computers in all facets of psychology. The annual meeting is held the day before the Psychonomic Society meeting in the same location. Over the years, many ground-breaking techniques for the use of computers in psychological research and teaching have been first presented at this conference. These studies often later find their way into this journal, either in this special issue or as regular contributions. If you have any interest in the use of computers in psychology and are going to the Psychonomic Society Annual Meeting, it would be worth arriving a day early to take in this important conference.

\section{The 2005 Annual Meeting}

The one-day conference was held at the Sheraton Centre in Toronto, Ontario, on November 10,2005 . The program included more than 50 stimulating presentations in eight paper sessions and one poster session. The papers covered a wide range of computer-based techniques, including instruction and research, modeling, software design, and a retrospective on 10 years of Web-based research. The first papers on Web-based research were presented at SCiP in 1995. The program chair for the 2005 meeting was Kay Livesay. Chris Wolfe delivered the Presidential Address, "Cognitive Technologies for Gist Processing." This paper is included in this issue. Goeffrey Hinton presented the Keynote Address, "Can Computer Simulations of the Brain Allow Us to See Into the Mind?" The 2005 Castellan student paper award winner was Cyrus Shaoul, for the paper "Toward a More Psychologically Relevant High-Dimensional Model of Lexical Semantics."

The SCiP articles included in this issue were contributed to BRM and reviewed by the journal's consulting editors, members of the steering committee of the SCiP conference, and ad hoc reviewers who have expertise in each paper's area. I thank all of the reviewers for their important contributions to the quality of these papers.

\section{The 2006 Annual Meeting}

The 36th Annual Meeting of SCiP will be held at the Hilton Americas Hotel in Houston, Texas on November 16, 2006, just before the annual meeting of the Psychonomic Society. The Call for Papers may be found at www.scip.ws. Presentations geared for all levels are appropriate, including introductory tutorials, new ways of teaching or collecting data, and technical information for researchers and programmers. Individuals interested in suggesting a topic for a symposium or submitting a paper for the 2006 meeting are urged to contact the program chair, Curt Burgess, with questions or comments.

Curt Burgess

Department of Psychology

University of California, Riverside

900 University Avenue

Riverside, CA 92521

curt@ucr.citrus.edu

\begin{abstract}
About the Society for Computers in Psychology
Membership in SCiP and participation at the meeting are open to all who are interested in the uses of computers in psychological research, teaching, and applications. Information about joining SCiP or participating in its meetings may be obtained from the Web page (www.scip.ws) or from Secretary-Treasurer Kay Livesay, Linfield College (klivesa@linfield.edu). Students are welcome to join the society and participate in its meetings. The John Castellan award is given for the best student paper presented at the conference.
\end{abstract}


The president of SCiP for 2005-2006 is Ulf Reips, Universität Zürich; the past president is Chris Wolfe, Miami University (Ohio); and the president-elect is Roman Taraban, Texas Tech University. Kay Livesay is secretary-treasurer. The other members of the steering committee are Katja WiemerHastings, Northern Illinois University; Gary Bradshaw, Mississippi State University; Anne Britt, Northern Illinois University; Xiangen Hu, University of Memphis; Bill Maki, Texas Tech University; Jonathan Vaughan, Hamilton College; John Eustis Williams, University of Northern Iowa; and Peter Foltz, New Mexico State University. Xiangen Hu is webmaster.

John Krantz

Hanover College 